\title{
Long Term Assessment of a Grid Connected Solar PV System in Sydney
}

\author{
Saad Odeh \\ Science and Engineering Program, Western Sydney University - City Campus, and Sydney Institute of Business and Technology, \\ NSW 2000, Australia
}

Received: July 21, 2016 / Accepted: August 8, 2016 / Published: October 31, 2016.

\begin{abstract}
This paper assesses 4 years of operation of a $1.75 \mathrm{~kW}$ roof top solar PV system installed in a Sydney suburban house. The system consists of $10 \mathrm{PV}$ panels, a DC/AC inverter, and a grid connected gross meter. Solar electricity delivered to grid is verified with the results from a computer simulation package (PVSYST) by adopting the installed component specifications, operation conditions, and weather data of the site. The results show high consistency between the values of energy delivered to the grid measured by the energy company and the energy estimated by system simulation. New system performance indicator is developed and called the optimum performance compliance ratio $\left(P_{C R}\right)$. It is a measure of the compliance of the output of the designed PV system with the output which would be produced by the same system with a solar tracker. This indicator provides system designers, contractors and energy providers with the actual capacity of the system that they can offer the end-users.
\end{abstract}

Key words: Long term assessment, grid connected PV system, solar electricity, performance indicator.

\section{Introduction}

The global solar PV power generation market has experienced significant increase since 2008. It is estimated that the residential PV system capacity represents between $25 \%$ and $35 \%$ of the global PV capacity which is reached to about $140 \mathrm{GW}$ [1]. The Australian market for PV installations experienced growth during the last six years due to incentives of the Australian Government's RET (renewable energy target) mechanism and other incentives provided by grants from ARENA (Australian Renewable Energy Agency), and the CEFC (Clean Energy Finance Corporation). The renewable energy target consists of two parts: the LRET (large scale) which is mainly for commercial systems, and the SRES (small scale renewable energy scheme) which is targeting residential application systems [2]. The estimated total

Corresponding author: Saad Odeh, Ph.D. in mechanical engineering, research fields: solar thermal and PV systems performance.
PV capacity installed by residential sector in Australia reached around 4,918 MW by March 2016 [3].

Grid connected solar PV system installations in residential sector were started in NSW (New South Wales)-Australia in large scale after the launch of the solar bonus scheme in 2010 which provided a feed-in tariff for PV systems of a capacity not more than $10 \mathrm{~kW}$ output. 320,000 households in NSW have benefited from the scheme and the estimated solar power installed by July 2015 was 820 MW [4].

Few papers in the literature reported the long term performance of the roof top residential PV systems connected to the grid. Watt et al. [5] reported the actual performance of different residential PV systems installed in NSW-Australia of a capacity $1.6 \mathrm{~kW}$ and 1 $\mathrm{kW}$. One year of energy supplied to grid was analyzed and the performance ratio for each site was calculated. The average yearly performance ratio achieved at these sites was found equal to $65-70 \%$.

Long term assessments for grid connect PV systems for residential power generation were conducted for 
eleven main cities in Queensland-Australia using a computer simulation [6]. The impact of PV panel slope on energy fed to grid, investment cost, financial income, and $\mathrm{CO}_{2}$ emission were also studied. It was found that for all cities considered in this study the optimum design is when panel slop is between $20^{\circ}$ and $25^{\circ}$.

An online model was developed to predict output power and energy efficiency of solar photovoltaic system and validated with measured data of grid connected system in Ref. [7]. The model results fit very well with the real operation during the day time period 9 am to $4 \mathrm{pm}$, however it could not predict early morning and afternoon hours precisely.

The output of a $1.72 \mathrm{~kW}$ rooftop grid connected PV system in Ireland was recorded and analyzed to evaluate the annual final yield, performance ratio, PV module efficiency, system efficiency, and system different losses [8]. The results of performance indicators evaluated at this site were compared with the results at different sites in Europe and shown superiority among others only in reference yield where its value was found quite below the average.

In this paper, 4 years of solar electricity generation from a rooftop PV system located in Sydney is analyzed. The amount of energy fed to grid quarterly is concluded from the energy bill and analyzed against total solar irradiation measured by a local weather station. The collected data of system output are analyzed and high consistency with PVSYST simulation output is reported. The new method of benchmarking the PV system is introduced and compared with the currently used performance indicators. This paper gives guidelines for the energy companies and the local government on how to estimate the actual amount of energy fed to the grid by the rooftop PV system and highlights the major factors affecting system performance.

\section{Roof Top PV System Description and Operation Features}

The system used in the performance analysis of this work was installed in 2011 at a suburban house in Sydney. Fig. 1 shows 10 PV panels (175 W each) installed on the northern roof of the house. The PV panel array consists of two PV strings connected in parallel. The PV panel is selected in a way that its voltage and current at extreme winter or summer temperatures fall within the inverter voltage and current window (see Table 1). Such type of PV array arrangement allows for maximum power output and optimum invertor operation. High temperature increases the panel surface temperature and consequently may drop the panel output in the range of 4-10\% [9]. Contrarily, low ambient temperature decreases PV surface temperature and may increase PV array output by the same percentage.

The highest and lowest daily temperatures during the years of system operation were found equal to $9.6{ }^{\circ} \mathrm{C}$ and $46{ }^{\circ} \mathrm{C}$ respectively [10]. Another factor affecting PV panel temperature is the wind and air circulation above and underneath panel surface. The current installation of the PV array is elevated $120 \mathrm{~mm}$ above the roof surface which allows air circulation underneath the panels by natural circulation. Wind data measurement shows that average wind speed in summer is higher than winter and reaches about $6 \mathrm{~m} / \mathrm{s}$ during day time. This improves heat loss by convection from the PV panel surface and thus improves the panel efficiency.

The AC output power from the inverter is fed to the local grid through a gross meter. This meter exports the generated electricity directly to the local energy provider (Energy Australia). In the meantime, the household load is imported from the grid from the same gross meter. The DC and AC wiring between the PV array and the invertor and between the invertor and

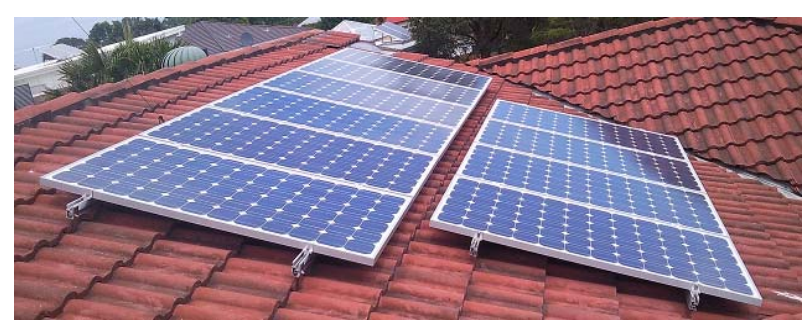

Fig. 1 PV panels installed on the house northern roof. 
Table 1 Summary of the system specifications and operation conditions.

\begin{tabular}{|c|c|}
\hline Site latitude & $33.5^{\circ} \mathrm{S}$ \\
\hline Roof tilt and azimuth angles & $23^{\circ}$ and $10^{\circ}$ \\
\hline Type of PV panel & $\begin{array}{l}175 \mathrm{~W} \text { mono crystalline } \\
\text { silicon }\end{array}$ \\
\hline PV array type and nominal power & $\begin{array}{l}2 \text { parallel string of } 1.75 \\
\mathrm{~kW} \text { output at STC }\end{array}$ \\
\hline $\begin{array}{l}\text { Voltage and current at maximum } \\
\text { power point }\end{array}$ & $164 \mathrm{~V}$ and $9.6 \mathrm{~A}$ \\
\hline Total area of PV panels & $12.8 \mathrm{~m}^{2}$ \\
\hline DC/AC inverter type & $\begin{array}{l}\text { SMA, Sunny Boy } \\
\text { SB1700 }\end{array}$ \\
\hline Range of inverter operating voltage & $139-320 \mathrm{~V}$ \\
\hline Type of grid connected meter & Gross meter \\
\hline Length of DC and AC wiring & $20 \mathrm{~m}$ and $30 \mathrm{~m}$ \\
\hline $\begin{array}{l}\text { Distance of the weather data station } \\
\text { from the site }\end{array}$ & $4 \mathrm{~km}$ \\
\hline Period of the collected data & 2/3/2011-15/10/2015 \\
\hline
\end{tabular}

gross meter are designed with minimum length to reduce drop in voltage. Since the first day of operation, this system has not undergone any maintenance or cleaning process such as removal of dust or dirt from the PV array upper surface. The only cleaning process is basically performed by the natural fall of the rain which occurs in the four seasons. The average rain fall in Sydney is variable and reaches its maximum in December (169.6 $\mathrm{mml} / \mathrm{month}$ ) and minimum (9 $\mathrm{mml} / \mathrm{month}$ ) in July [10].

The Australian standard for PV system installation has been achieved by considering the following regulations:

(1) NSW Service and Installation Rules;

(2) ASNZS3000 and Energy Australia's Electrical;

(3) Clean Energy Council rules for design and installation of the solar PV grid connected system.

Table 1 presents the summary of the PV systems main specifications.

\section{Long Term Performance Assessment and Computer Model Validation}

The roof mounted system was installed early in 2011 and four years of electricity data fed to the grid from 2011 to 2015 were analyzed and presented in Fig. 2. Electricity is fed to grid through a gross meter that exports all the PV system output directly to the grid. The gross meter data are reported quarterly (every 3 months) in kWh by the local energy provider (Energy Australia). Fig. 2 shows high consistency of energy production during the four years of operation with some small dip and rise based on the incident global irradiation. It can be concluded from Fig. 2 that the average long term power generation efficiency (output divided by global irradiation) is about $10.9 \%$. The maximum energy fed to grid occurs during the quarters $4,8,12$, and 16 which represents the summer period in the year 2011, 2012, 2013, and 2014. Alternatively minimum energy production occurs during the quarters $2,6,10,14$, and 18 which represents the winter period in these years.

System output was registered by the local energy provider company (Energy Australia) for three daily periods of grid load: peak, shoulder and off peak period. The outputs during each period are summarized in Fig. 3. It is clear that maximum system output occurs during the shoulder period which covers the time from 7 am to $2 \mathrm{pm}$. The energy generated during this period represents between $75 \%$ and $87 \%$ of yearly energy output. The maximum amount of energy fed to grid occurs during the quarter October-January for both peak and shoulder time. While the minimum load spread over two quarter periods April-July for peak load, and Jan.-April for the shoulder load.

The off peak period output is almost negligible in different seasons since the solar elevation angle before $7 \mathrm{am}$ is quite high and solar irradiation is too low. For this type of PV system output profile it can be concluded that net metering (selling surplus energy from household to grid) is more convenient than gross metering (selling all energy production to grid). This can be justified since the current price of selling solar electricity to the grid in Australia is in the range of $5-20 \mathrm{k} / \mathrm{kWh}$ which is much lower than the price of buying conventional electricity from the grid during the peak load period which reaches up to $40-46 \mathrm{\$} / \mathrm{kWh}$. 


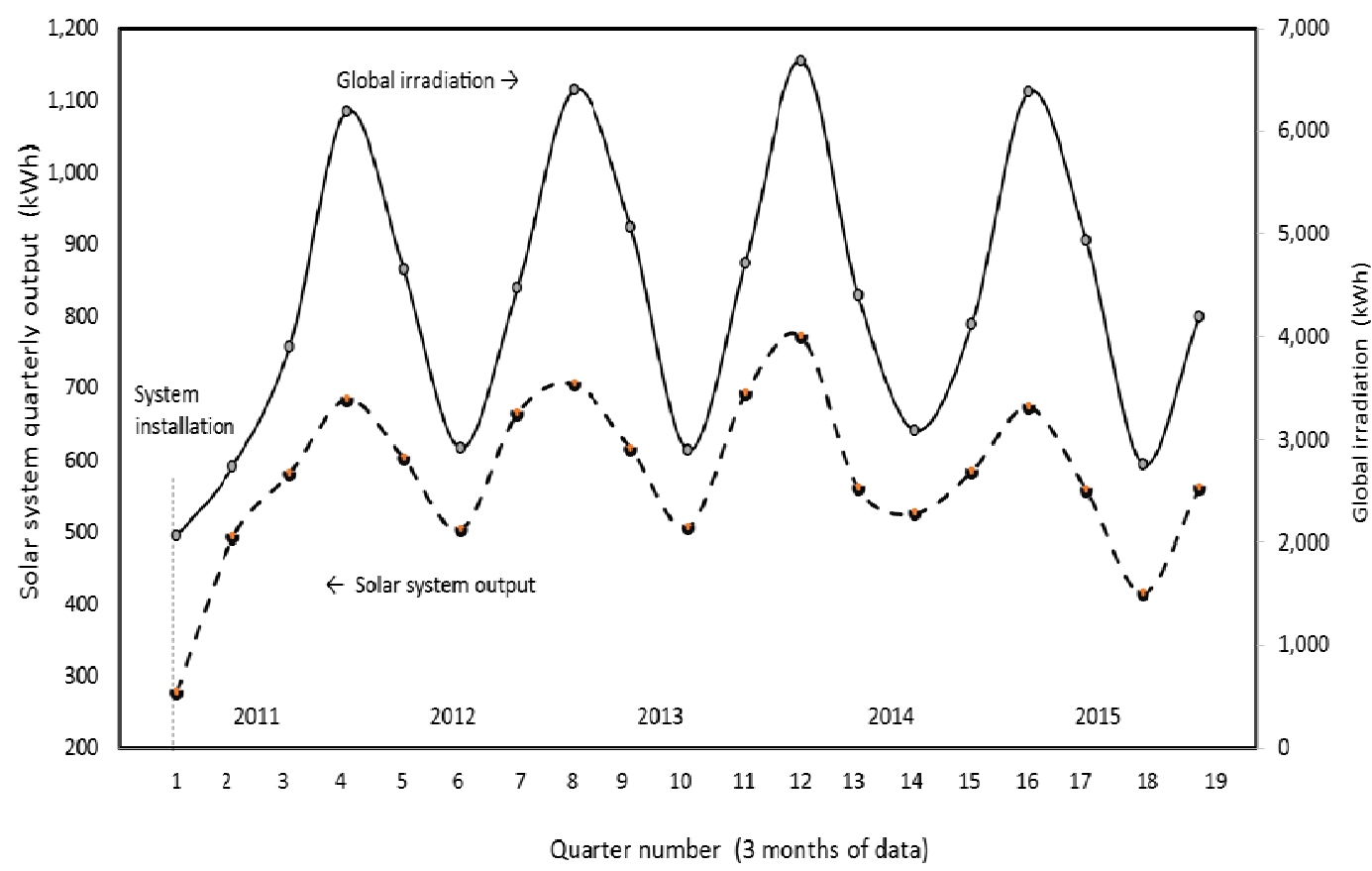

Fig. 2 Electricity fed to grid and total global irradiation incident on the PV array every quarter.

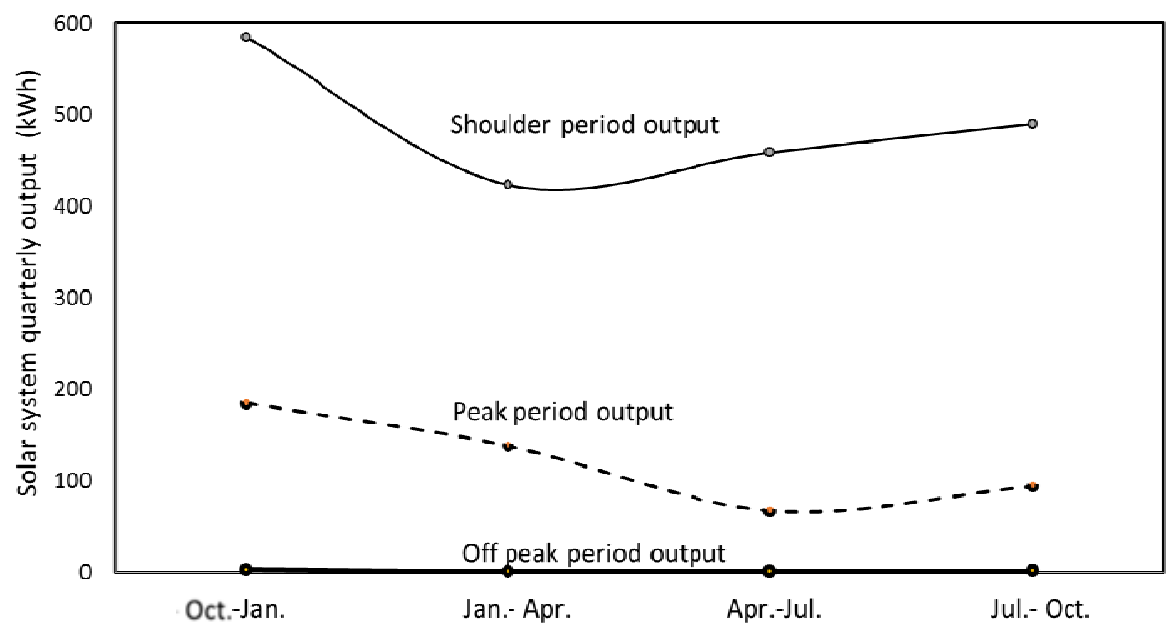

Fig. 3 System output during different load periods: peak 2 pm to 8 pm, shoulder 7 am to 2 pm, 8 pm to 10 pm, and weekend 7 am to $10 \mathrm{pm}$, off peak others.

To have comprehensive analysis of the long term performance system simulation was performed using the PVSYST package. Validation of this package was conducted by comparing its results with the reported data for the same period of time to find out its consistency and percentage of error. Fig. 4 shows that the PVSYST correlates the measured data with high accuracy in most of the year with relative error in the range of $( \pm 4.4 \%)$. The maximum error occurs during winter quarter which is about $12 \%$ due to the difference between the actual weather data and the data bank of the PVSYST package.

The PVSYST package was used to find yearly system losses and the result is presented in Fig. 5. The major losses are related to system design and installation such as: Incident angle modifier IAM 3.1\%, the increase in PV surface temperature 5.8\%, DC and AC wiring loss $1.9 \%$, and inverter loss during operation $7.7 \%$. 


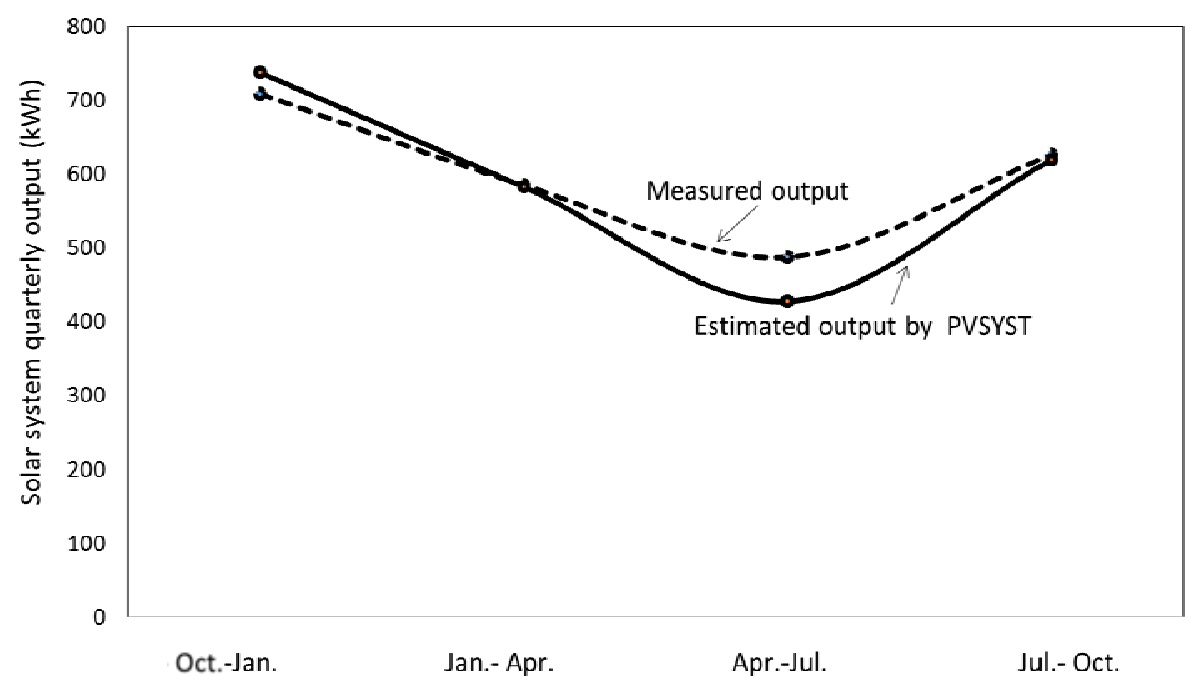

Fig. 4 Validation of the simulation package PVSYST with the measured data.

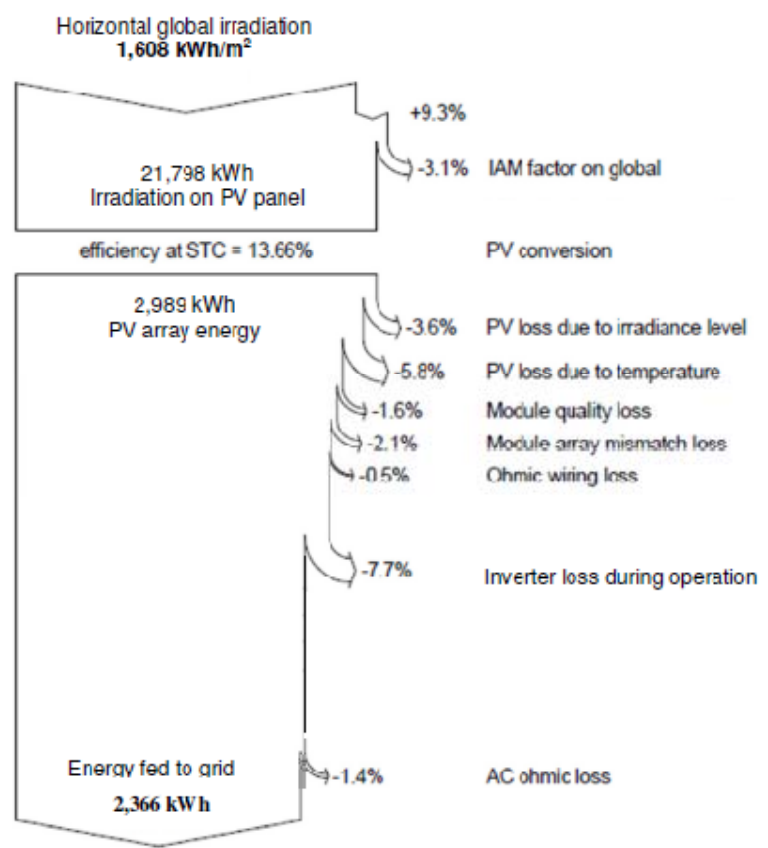

Fig. 5 Yearly energy loss diagram of the roof top PV system.

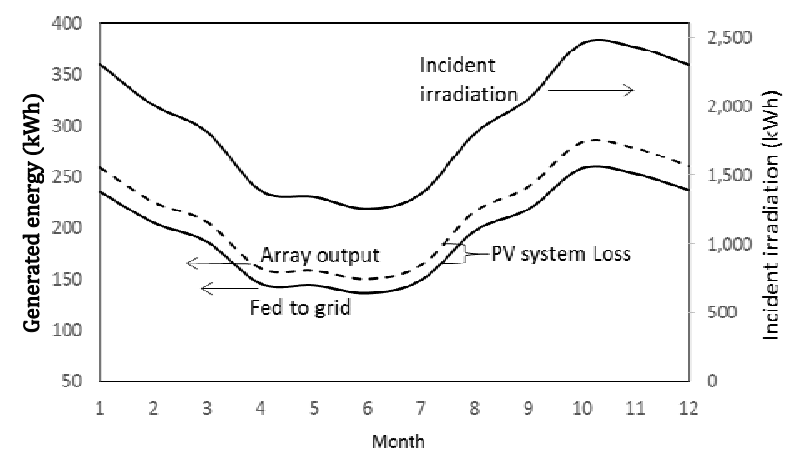

Fig. 6 Monthly performance of the PV system.
The monthly performance presented in Fig. 6 shows that maximum energy production in the year occurs during October. The difference between array output and energy fed to grid represents the energy loss in the systems. It appears in Fig. 6 that this energy loss does not change much during the year. The slight increase in the energy loss during hot and warm season is due to the increase in PV surface temperature.

\section{Benchmarking the PV System Performance}

Many types of methods are used to assess the long term performance of the power generators of different energy sources such as: oil, gas, coal, renewable, etc. Although these assessment methods are applicable to the different power generator, solar power generators require some other considerations. The intermittent solar irradiation, system orientation, and of other weather conditions affect dramatically the long term performance [9]. The major performance assessment methods of solar PV power generators found in the literature are summarized by the following five indicators:

(1) System efficiency ( $\eta_{\text {system }}$ ); which is simply the ratio of the output energy to the energy from the incoming irradiation on the same PV system area and is given in the following form $[11,12]$ : 


$$
\eta_{\text {system }}=\frac{\text { Generated enery in } k W h \text { from the } P V \text { system }}{\text { Energy of global solar irradiation in } k W h \text { received by } P V \text { array area }}
$$

Since the input energy used in this method is the solar irradiation on the PV surface area, the calculated system efficiency is quite low (10-12\%) and depends significantly on the PV panel efficiency (13-15\%) and inverter efficiency (95-98\%). This method is useful when it is required to compare the different designs and brands of PV systems. However, from the end user point of view the low value of system efficiency is not a strong selling point for these systems because low efficiency cannot be justified if it is compared with other types of traditional power generation units.

(2) Solar fraction (SF); which is the amount of energy produced by the PV system to the amount of load required at the respective site [13]. The value of solar fraction depends mainly on the PV system contribution to the site load and cannot be used to compare system performance with other similar systems at different sites. Furthermore long term system capacity cannot be identified by this method.

$$
S F=\frac{\text { Generated enery in } k W h \text { from the } P V \text { system }}{\text { Site energ load (heat and/or electricity) in } k W h}
$$

There is no specific range for the value of $S F$ because it depends on the percentage of solar contribution to the site energy load, yet from the economic perspective $S F$ cannot approach $100 \%$ due to the requirement of the costly energy storage battery bank to cover the periods of low or zero irradiation.
(3) Performance ratio $\left(P_{R}\right)$ : which represents the amount of energy produced by a PV system to the energy which would be produced by the same system operating continuously at STC (standard test conditions) and same global irradiation [14-16] and it can be represented by this equation:

$$
P_{R}=\frac{\text { Actual energy produced by a PV system }(k W h)}{\text { Energy which would be produced by the same system at STC }(k W h)}
$$

$P_{R}$ values are typically evaluated on a monthly or yearly basis by including system losses and it is independent of system size. In some cases $P_{R}$ calculated for smaller intervals, such as weekly or daily, to investigate the occurrences of component failures. The average value of the performance ratio is found in the literature within the range of 0.6 to 0.8 .

(4) The final PV system yield or the PV system specific power production $\left(Y_{f}\right)$. It is the actual net energy output divided by the maximum installed power capacity of the PV array and has the unit $\left(\mathrm{kWh} / \mathrm{kW}_{\mathrm{c}}\right)$, thus $[8,14,16]$ :

$$
Y_{f}=\frac{\text { Energy produced by the PV system }(k W h)}{P V \text { array maximum capacity }(k W)}
$$

$Y_{f}$ is a convenient way to compare the energy produced by PV systems of different sizes. The average value for $Y_{f}$ found in the literature is between 1.4 and $4.8 \mathrm{kWh} / \mathrm{kW}_{\mathrm{c}}$.
(5) Capacity Factor $\left(C_{F}\right)$ is defined as the ratio of the actual annual energy output from The PV system to the amount of energy the PV system would generate if it is operated at its full rated power 24 hours a day [8], thus:

$$
C_{F}=\frac{\text { Energy produced by the } P V \text { system }(k W h) / \text { year }}{\text { PV array maximum capacity }(k W) \times 8760 h / \text { year }}
$$

The annual average value for $C_{F}$ achieved by the work of Ayompea et al. [8] was 10.1\%.

\section{Proposal for New Definition of the PV Performance Indicator}

The performance indicators $P_{R}, Y_{f}$, and $C_{F}$ introduced in Eqs. (3)-(5) benchmark the performance of the solar PV grid connected system to the standard test condition which assumes that:

(1) Solar radiation is always normal to PV surface;

(2) Solar radiation is maximum $\left(1,000 \mathrm{~W} / \mathrm{m}^{2}\right)$;

(3) Average ambient temperature is $25^{\circ} \mathrm{C}$; 
(4) Air mass of 1.5;

(5) System losses (e.g., wiring, invertor, etc.) are not considered.

The above standard operation conditions (2 to 5) cannot be achieved constantly during the actual operation of the solar PV system in another word, it is a state of hypothetical operation and it can only be achieved by laboratory virtual conditions. Considering these arbitrary conditions in the performance indicator of a solar PV system will underestimate the actual value of the performance indicator.

In general the energy capacity $\left(E_{c}\right)$ of a conventional power generator is specified by its power capacity $\left(P_{c}\right)$ during full load operation and it is calculated by:

$E_{c}=P_{c} \times$ number of operation hours

Eq. (6) shows that a full load operation of a generator may reach its maximum when it is operated full time (daily, monthly or yearly). This type of operation cannot be achieved by renewable energy systems and specifically the solar PV system since its output is limited to the following real conditions:

(1) Number of sun shine hours during the year;

(2) Site Irradiation and weather conditions during the year;

(3) PV array orientation and inclination.

Therefore it is not correct to specify the energy capacity of a $1 \mathrm{~kW}$ PV panel by referring to Eq. (6) because the above real conditions frame its yearly output and nothing can be generated beyond this limit. Based on this fact and from the end-user perspective PV system capacity must be readjusted for each site based on its real condition. The end-user should not be penalised financially for the unreachable STC.

The PV array orientation and inclination loss can be eliminated at a certain location when the solar beam is kept normal to PV surface from sunrise to sunset (i.e., when the PV panel is controlled by a solar tracker). Such type of tracking mode allows the PV system to produce its maximum yearly energy output. Based on this fact the performance ratio $\left(P_{R}\right)$ and the capacity factor $\left(C_{F}\right)$ given by Eqs. (3) and (5) can be adjusted and represented by new performance indicator called the optimum performance compliance ratio $\left(P_{C R}\right)$ given by the following equation:

$$
P_{C R}=\frac{E_{p}}{E_{\max }}
$$

where,

$E_{P}$ : Energy produced by the actual PV system (kWh/year).

$E_{\text {max }}$ : Maximum energy produced by the same PV system with two axis solar tracking mode $(\mathrm{kWh} / \mathrm{year})$.

The optimum performance compliance ratio $\left(P_{C R}\right)$ given by Eq. (7) is a measure of the compliance of the PV system output to the optimum design (solar tracking system) output. This indicator provides system designers, contractors and energy providers with actual picture of the PV system size offered to the end-users. For example, if a system of $1.5 \mathrm{~kW}$ is required to be installed in two different sites with different roof orientation their cost price $(\$ / \mathrm{kWh})$ must be adjusted to the $P_{C R}$ value because this is the actual output that the end-user receives and not the PV panel output at STC condition.

Fig. 7 shows the difference between the roof mounted system of this work and the solar tracking PV system output. The monthly output of the roof mounted system is always below the solar tracking system in the range of $21-28 \%$. Therefore, this difference in system output will cause the proposed $P_{C R}$ ratio follows different trend from other traditional performance indicators such as the $P_{R}$. This is quite obvious in Fig. 8 which shows the variation of the two indicators during the whole year. The proposed $P_{C R}$ ratio shows that the PV system of this study has the lowest compliance to the optimum design performance in winter season in contrast to the $P_{R}$ ratio which shows system performance is optimum in winter. The proposed $P_{C R}$ indicator considers the optical loss (cosine loss) and compares the system output with zero cosine loss case which is the solar tracking system. Therefore, the $P_{C R}$ ratio drops down in winter due to the low solar elevation angles which maximize the optical losses of 


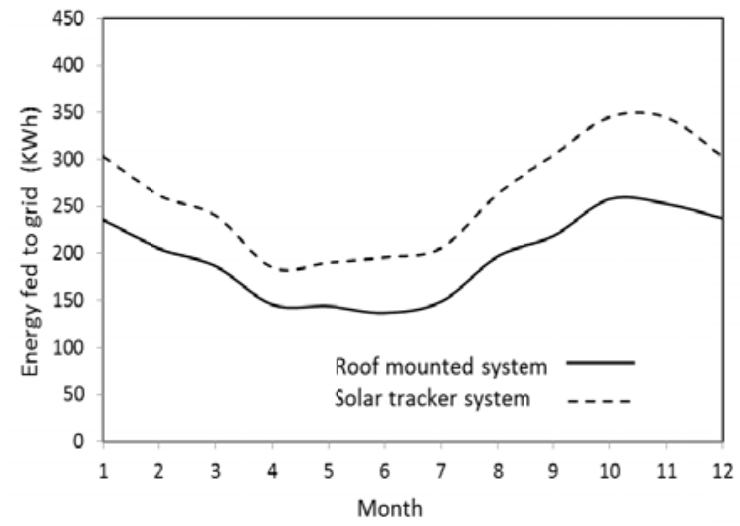

Fig. 7 Comparison between roof mounted and solar tracking PV system output.

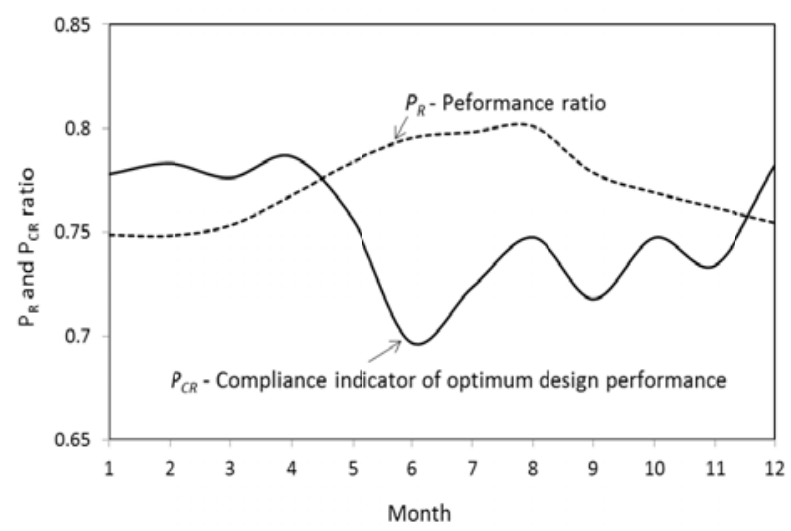

Fig. 8 Monthly $P_{R}$ and $P_{C R}$ values of the roof mounted PV system.

the roof top system. Fig. 8 shows that the annual average ratio of both indicators $P_{C R}$, and $P_{R}$ for the system of this study are 0.75 and 0.77 , respectively.

\section{Conclusions}

This paper assessed the long term operation of a roof top solar PV system installed in a Sydney suburban house. The four years of energy fed to grid provided by Energy Australia showed that system performance was steady and has quite similar yearly output during the four years. The operation analysis showed that maximum system output occurs during shoulder period of the grid and represents $75-87 \%$ of the yearly energy output. Solar electricity delivered to the grid was verified with PVSYST package results and high consistency in energy fed to the grid between the actual and the simulated system was reported. Major losses in PV array output were found related to the system design and installation such as: incident angle modifier $3.1 \%$, PV surface temperature $5.8 \%$, wiring loss $1.9 \%$, and inverter loss during operation $7.7 \%$.

Different types of PV system performance indicators were presented. A new performance indicator called optimum performance compliance ratio $\left(P_{C R}\right)$ was developed and suggested to be used by designers and energy providers to estimate the actual output that includes different operation losses. The developed performance indicator $P_{C R}$ measures the compliance of a PV system output with the optimum design output that would be produced by the same system with a solar tracker. The study showed that the cost price $(\$ / \mathrm{kWh})$ of a PV system must be adjusted to the $P_{C R}$ value because this is the actual output that the end-user receives and not the PV panel output at the STC condition. Future work will focus on the effect of different design conditions on the $P_{C R}$ ratio and its impact on system costing and the tariff of energy fed to the grid.

\section{Acknowledgment}

The author would like to thank Felicity Orme, the academic director, Western Sydney University-City Campus, and Sydney Institute of Business and Technology, for the valuable comments that greatly improved the manuscript.

\section{References}

[1] Cáceres, G., Nasirov, S., Zhang, H., and Araya-Letelier, G. 2015. "Residential Solar PV Planning in Santiago, Chile: Incorporating the PM10 Parameter.” Sustainability 7 (1): 422-40.

[2] Fechner, H., Tabakovic, M., and Leonhartsberger, K. 2015. "National Survey Report of PV Power Applications in Austria 2014.” Austrian Institute of Technology.

[3] Clean Energy Regulator, Renewable Energy Target RET. 2016. Postcode Data for Small Scale Installations, Australian Government. Accessed July 16, 2016. http://www.cleanenergyregulator.gov.au/Document Assets/Pages/Postcode-data-for-small-scale-installations. aspx.

[4] NSW Government. 2015. Department of Industry, Skills and Regional Development-DISRD. NSW renewable energy action plan annual report. 
[5] Watt, M. E., Morgan, R., and Passey, R. J. 2006. "Experiences with Residential Grid-Connected Photovoltaic Systems in Australia.” Australian and New Zealand Solar Energy Society.

[6] Liu, G., Rasul, M., Amanullah, M., and Khan, M. 2012. "Techno-Economic Simulation and Optimization of Residential Grid-Connected PV System for the Queensland Climate.” Renewable Energy 45 (September ): 146-55.

[7] Su, Y., Chan, L., Shu, L., and Tsui, K. 2012. "Real-Time Prediction Models for Output Power and Efficiency of Grid-Connected Solar Photovoltaic Systems.” Applied Energy 93 (May): 319-26.

[8] Ayompea, L., Duffya, A., McCormackb, S., and Conlonc, M. 2011 "Measured Performance of a 1.72 kW Rooftop Grid Connected Photovoltaic System in Ireland.” Energy Conversion and Management 52 (2): 816-25.

[9] Odeh, S., and Behnia, M. 2009. "Development of PV Module Efficiency Using Water Cooling.” Heat Transfer Engineering Journal 30 (6): 499-505.

[10] Bureau of Meteorology. 2016. Australian Government, Climate Data Online. Accessed May 10, 2016. http://www.bom.gov.au/climate/data/.

[11] Ueda, Y., Kurokawa, K., Itou, T., Kitamura, K., Akanuma, K., Yokota, M., and Sugihara, H. 2008. "Advanced
Analysis of Grid-Connected PV System's Performance and Effect of Batteries.” Electrical Engineering in Japan 164 (1): 247-58.

[12] Odeh, S., and Abu-Mulaweh, H. 2012. "Design and Development of Experimental Setup of Hybrid PV/Thermal Collector.” Global Journal of Engineering Education 14 (2): 170-6.

[13] Fujisawa, T., and Tani, T. 2001. “Optimum Design for Residential Photovoltaic-Thermal Binary Utilization System by Minimizing Auxiliary Energy.” Electrical Engineering in Japan 137 (1): 28-35.

[14] Marion, B., Adelstein, J., Boyle, K., Hayden, H., Hammond, B., Fletcher, T., Canada, B., Narang, D., Shugar, D., Wenger, H., Kimber, A., Mitchell, L., Rich, G., and Townsend, T. 2005. "Performance Parameters for Grid-Connected PV Systems.” In Proceedings of the 31st IEEE Photovoltaics Specialists Conference and Exhibition, NREL/CP-520-37358.

[15] Jahn, U., and Nasse, W. 2004. "Operational Performance of Grid-Connected PV Systems on Buildings in Germany.” Progress in Photovoltaics: Research and Applications 12 (September): 441-8.

[16] Mermoud, A. 2012. PVSYST Photovoltaic Software. The University of Geneva, Switzerland. 